\title{
Transitions and prospects
}

\section{Brian D Johnston}

This issue marks the end of my 10-year term as editor-in-chief of Injury Prevention. Rod McClure, the incoming editor, will assume his responsibilities with the next volume. I am extraordinarily pleased with his selection and look forward to seeing the evolution of the journal under his competent stewardship. As the transition approaches, I would like to offer a few thoughts and ideas from my time with the journal and the privileged position it has given me to observe our field and the many academics and practitioners who work therein.

I believe we have made progress over the last decade. It's an exciting time to work in injury control. New opportunities and new issues arise daily. And while I don't presume to know what is best for the field, there are some overarching themes that I think bear recognition.

We are getting better at gathering data for prevention. The Global Burden of Disease estimates are remarkable in their scope and inclusiveness ${ }^{1}$; they should drive policy and priority setting. But to do so, they must be updated continuously, their models tested and refined against available data, and their limits recognised. If there are gaps in the raw data needed to generate meaningful regional, national, or subnational estimates, we must identify these and call for their collection. One-off well-conducted community surveys are likely to be more useful in these situations than are elaborate ongoing surveillance systems. And let's be sure that the data collected, along with the evidence thus created, are handed back to the individuals, communities, and organisations who have collected it and whose well-being it reflects. $^{2}$

But descriptive epidemiology is only the beginning. We actually need fewer studies about incidence, burden, and risk factors and more trials of preventive interventions. What works to control injury? Why does it work? And how can we bring our learning to scale, disseminate it into new contexts and make its programmes sustainable? I think the key will be found in our willingness to weave

Correspondence to Dr Brian D Johnston, Department of Pediatrics, University of Washington, Seattle, WA 98104, USA; bdj@uw.edu injury control policies and initiatives into a variety of sectors: programmes to promote active transport can include promotion of safer walking and biking; accessible early child care will promote development and literacy butmay also reduce unintentional injury by keeping children in safer, supervised environments; and policies to address economic injustice may also reduce violence and self-harm.

Indeed, a major cross-sectoral opportunity looms in terms of urban form and planning. ${ }^{3}$ In the century ahead, most people will be living in cities and most of the urban infrastructure that will support those people has not yet been built. Development is happening at breakneck speed. China is both a locus of that development and an active partner in development elsewhere throughout the global south, and thus could be especially influential in this respect. ${ }^{4}$ We need to identify design principles, techniques, and priorities that will engineer safety into the urban form and the modes of living, working, and playing that unfold there. Balancing cost and acceptability with efficacy is crucial, and getting policymakers and developers to align with this agenda even more so. The sustainable development goals provide a reasonable framework from which to launch these efforts.

On a more modest level, the journal too has seen change and will face some challenges. Transparency has been a recurrent theme and an area where we could continue to improve. I have lobbied for more detailed methods reporting (published as study protocols), access to statistical coding files and to data housed in a repository. ${ }^{56}$ Making these available to readers encourages accountability and replicability, hallmarks of any mature science. Even greater transparency in the publication process can be achieved through open peer review, a system that incidentally might make it easier to recognise and academically reward thoughtful peer feedback.

Open access is a persistent demand from many readers. We have settled for now on a hybrid model, with special efforts made to ensure availability in lower resourced settings. The hard reality is that many researchers in our discipline are unfunded and cannot muster open access fees. Still, I feel strongly that journals add value; there is a need for content curation and managing the process of peer review and postpublication feedback. Issues with plagiarism, research ethics and the standards of reporting alone mandate some form of editorial oversight. So we will continue to juggle the costs of publication and the legitimate need to share (properly reviewed) information widely.

We have also worked to enhance our presence in the social sphere. Our blogs, Facebook, Twitter and other accounts are active, thanks to the energy of Bridie Scott-Parker and her team. But we could use a more robust social media strategy in order to develop our virtual presence for the benefit of both authors and readers. We have article-level altmetrics now, which integrate these media impressions into impact scores that may be more meaningful for a digital generation. Ultimately, I believe we need to become a digital-only journal. Most readers interact with the journal online, yet significant editorial and production effort goes into defining and creating discrete issues that are only relevant to reading on paper. This is a decision for the publisher, but I think the transition would benefit the journal and keep it relevant for decades to come.

Finally, and fittingly, I would like to close with my thanks. The BMJ group provides outstanding technical and editorial support to the journal with a crack team of publishing professionals in London and around the world. Their efficiency is surpassed only by their commitment to their people and to the highest standards of ethical practice. I am also grateful to Fred Rivara, my mentor, and to Barry Pless, our founding editor, for their thoughtful support. I recognise the tireless effort of my associate editors, Shanthi Ameratunga, Danilo Blank, Brent Hagel, Rebecca Ivers, Denise Kendrick, Will Pickett, Mark Stevenson and Flaura Winston. I have learnt so much from them and from the scores of our colleagues who have served on our editorial boards.

And it is the people, more than anything, whom I will remember. Injury control is a small discipline. Many of us work parallel careers as clinicians, educators or policymakers, but return to injury prevention for our research and academic work. This is often an act of faith and commitment. Funding for the field is dwarfed by the magnitude of the problem and our interdisciplinary focus tests the traditional, often siloed, systems of academic recognition and reward. But at every turn, I have encountered compassionate people working diligently, often heroically, on behalf of injury victims, in 
support of injury survivors, and to train the next generation of injury advocates. Our colleagues are creative, enthusiastic and generous with their time and ideas. It is a small family, to be sure, but a good one to which we all come home. Thank you.

Competing interests None declared.

Provenance and peer review Commissioned; internally peer reviewed.

(C) Article author(s) (or their employer(s) unless otherwise stated in the text of the article) 2017. All rights reserved. No commercial use is permitted unless otherwise expressly granted.

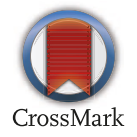

To cite Johnston BD. Inj Prev 2017;23:361-362.

Inj Prev 2017;23:361-362.

doi:10.1136/injuryprev-2017-042623

\section{REFERENCES}

1 Haagsma JA, Graetz N, Bolliger I, et al. The global burden of injury: incidence, mortality, disability- adjusted life years and time trends from the Global Burden of Disease study 2013. Inj Prev 2016;22:3-18.

2 Abdalla S. Injury modules in national surveys as a source of injury data in low and middle income countries. Inj Prev 2017;23:149-51.

3 Giles-Corti B, Vernez-Moudon A, Reis R, et al. City planning and population health: a global challenge. Lancet 2016;388:2912-24.

4 Johnston BD. Why China matters. Inj Prev 2014;20:147.

5 Johnston BD. Sharing data collection instruments. Inj Prev 2014;20:73.

6 Johnston BD. Living in the grey area: a case for data sharing in observational epidemiology. Inj Prev 2012;18:358-9. 